\title{
Hepatitis B virus: virology, molecular biology, life cycle and intrahepatic spread
}

\author{
P. Karayiannis ${ }^{1}$
}

Received: 11 July 2017/Accepted: 5 October 2017/Published online: 2 November 2017

(C) Asian Pacific Association for the Study of the Liver 2017

\begin{abstract}
Hepatitis B virus is a member of the Hepadnaviridae family and responsible for causing acute and chronic hepatitis in humans. The current estimates of people chronically infected with the virus are put at 250 million worldwide. Immune-mediated liver damage in these individuals may lead to the development of cirrhosis and hepatocellular carcinoma later in life. This review deals with our current understanding of the virology, molecular biology, life cycle and cell-to-cell spread of this very important pathogen, all of which are considered essential for current and future approaches to antiviral treatment.
\end{abstract}

Keywords Hepatitis B virus - Life cycle - Replication · Molecular virology $\cdot$ Genotypes · Cell-to-cell spread

\section{Introduction}

The burden of chronic infection due to hepatitis B virus (HBV) is currently estimated at around 250 million worldwide (WHO; fact-sheet no. 204, [1]), while deaths as a result of the chronic sequelae of the disease, such as cirrhosis, hepatocellular carcinoma (HCC) or liver failure, stand at 800,000 annually [2, 3].

Studies performed by Krugman and colleagues during the 1960s, particularly at the Willowbrook State School for mentally handicapped children, established the distinctive clinical, epidemiological, and immunological differences

\section{P. Karayiannis}

karayiannis.p@unic.ac.cy

1 Medical School, University of Nicosia, 21 Ilia Papakyriakou, 2414 Engomi, P.O. Box 24005, CY-1700 Nicosia, Cyprus between infectious hepatitis and serum hepatitis [4, 5]. These two entities were soon revealed to be due to infection with hepatitis A virus (HAV) or HBV, respectively. During the same period, work by Blumberg and colleagues led to the description of the Australia antigen detected in the sera of patients with leukemia, Down's Syndrome and hepatitis [6,7]. The connection between the Australia antigen, or hepatitis B surface antigen (HBsAg) as it is now known, and HBV, became apparent by 1970 [8]. Electron microscopic studies in the early 1970s led to the visualisation of the infectious virion or Dane particle [9], while detergent treatment of such particles exposed the nucleocapsid core of the virus [10]. This was followed by the characterisation of the virus genome, the virion-associated proteins and the detailed definition of the serological profiles in acute and chronic HBV infection [10-12]. Seminal work in Taiwan by Beasley and co-workers established the connection between the virus and the development of HCC [13].

Another historical landmark in HBV research was the introduction of the plasma-derived vaccine in the early 1980s, following extensive evaluation first in chimpanzees and then in the gay community of New York [14]. Concerns about the human immunodeficiency virus which appeared during that time and the safety of plasma-derived products in general, led to the development of a recombinant vaccine, which since its introduction has effectively reduced the prevalence of HBV infection in many countries of the world where the virus is still endemic [15].

Finally, great strides have been made in the treatment of chronic HBV carriers through the use of immunomodulators such as pegylated interferon-alpha (PegIFN $\alpha$ ), nucleoside analogues such as lamivudine (3TC), entecavir (Baraclude) and telbivudine (Tyzeka or Sebivo) or the nucleotide analogues adefovir dipivoxil (Hepsera) and 
tenofovir disoproxil fumarate (Viread) [16]. PegIFN $\alpha$ given for a finite period of 1 year acts by promoting lysis of infected hepatocytes through cytotoxic T cell action, while cytokines released control viral replication. Nucleos(t)ide analogues on the other hand which are given long term act as chain terminators at the stage of DNA synthesis. Viral suppression is achieved in about $25 \%$ of those treated with PegIFN $\alpha$, and this is more profound with the newer necleos(t)ide analogues, as they are more potent and have a high barrier to resistance [17].

Absence of a cell culture system for the propagation of the virus impeded the study of its life cycle and molecular biology for many years. This, however, changed in the early 1980s with the advent of genetic engineering techniques which made possible the cloning of the viral genome and its sequencing, investigation of the function of its proteins and unravelling the unique and fascinating mechanism of its replication strategy. The animal models of chimpanzees in the early days, and those of ducks and woodchucks, and more recently chimeric mice, have allowed the study of aspects of the life cycle, molecular biology and immune pathogenesis of the virus, and facilitated vaccine development and antiviral testing. What follows is a synopsis of the findings of many studies carried out using the above-described approaches, which have greatly improved our understanding of this very important pathogen.

\section{Virological perspectives}

\section{Classification}

The Hepadnaviridae family, with HBV as the prototype, is comprised of a group of hepatotropic DNA viruses which on the whole are species-specific and are divided into two genera. The Orthohepadnavirus genus includes members that infect mammals (woodchucks, ground squirrels, bats and primates) and have about $70 \%$ nucleotide homology between them. The Avihepadnavirus genus infects birds such as ducks (duck hepatitis B virus, DHBV), herons, storks, geese and parrots with about $80 \%$ homology between them. The homology, however, between the two genera is around $40 \%$, but nevertheless they share a common genomic organisation [18].

Nucleotide sequencing studies of human HBV isolates from around the world have established, based on sequence divergence of $>8 \%$, eight genotypes designated $\mathrm{A}-\mathrm{H}$, with characteristic geographical distribution. Genotypes A and $\mathrm{D}$ are frequently found in Africa, Europe, and India, genotypes B and C in Asia, genotype $\mathrm{E}$ is restricted to West Africa, and genotype $\mathrm{F}$ in Central and South America. Genotype $\mathrm{G}$ and $\mathrm{H}$ distribution is less clear, but isolates have been reported from Central America and southern Europe [18, 19], while possibly two new ones, genotype I from Vietnam, Laos and Eastern India appears to be an intergenotypic recombinant between genotypes $\mathrm{A}, \mathrm{C}$, and $\mathrm{G}$ [20], and genotype $\mathbf{J}$ isolated from a Japanese man who lived in Borneo, and which appears to be a recombinant between genotype $\mathrm{C}$ and gibbon HBV [21]. Genotypes A, $\mathrm{B}, \mathrm{C}, \mathrm{D}, \mathrm{F}$ and I can be further subdivided based on nucleotide divergence of $4 \%$ into at least 44 sub-genotypes; A1-6, B1-9, C1-16, D1-7, F1-4 and I1-2 [19, 22]. In addition, other than the above-mentioned recombinants, $\mathrm{B} / \mathrm{C}$ and $\mathrm{C} / \mathrm{D}$ recombinants represent the majority of such isolates, while other intergenotypic recombinants that occur less frequently involve most of the other genotypes [23].

\section{Virion structure and genome organisation}

The infectious virion or Dane particle of $42 \mathrm{~nm}$ in diameter is comprised of an outer envelope made of HBsAg in a lipid bilayer [9], wrapped around the nucleocapsid core of the virus, which in turn encloses the viral genome and a copy of its polymerase [9, 24]. In addition, there is an abundance of sub-viral particles circulating in serum consisting entirely of HBsAg and devoid of any nucleic acid containing cores. These are the $25-\mathrm{nm}$ spheres and the 22-nm diameter filaments, which outnumber infectious virions by 100 - to 10,000 -fold [25].

The partially double-stranded DNA genome of the virus is a relaxed circle of $3.2 \mathrm{~kb}$ in length (rcDNA) [26, 27]. In view of this, it is the smallest among DNA viruses and one of the most compact as the 4 open reading frames (ORFs) that the genome contains are either wholly or partially overlapping. Thus, every nucleotide of the genome forms part of an ORF. In addition, all regulatory elements such as the two enhancers (Enh1, Enh2), the four promoters (core, $\mathrm{S} 1, \mathrm{~S} 2$ and $\mathrm{X}$ ), polyadenylation, encapsidation $(\varepsilon)$ and replication (DR1, DR2) signals lie within these ORFs (Fig. 1).

\section{RNA transcription and protein translation}

The four ORFs are those of the surface (PreS/S), core (C), polymerase $(\mathrm{P})$ and $\mathrm{X}$ genes, which encode in total 7 proteins translated from six co-terminal, unspliced and capped mRNAs ending at a common polyadenylation signal, which is situated in the core ORF (Fig. 1, [29]). The aforementioned promoters and enhancers direct the synthesis of the mRNA transcripts through the recruitment of transcription factors which are particularly enriched in hepatocytes (reviewed in [30]). This in part also explains the liver tropism of the virus. 


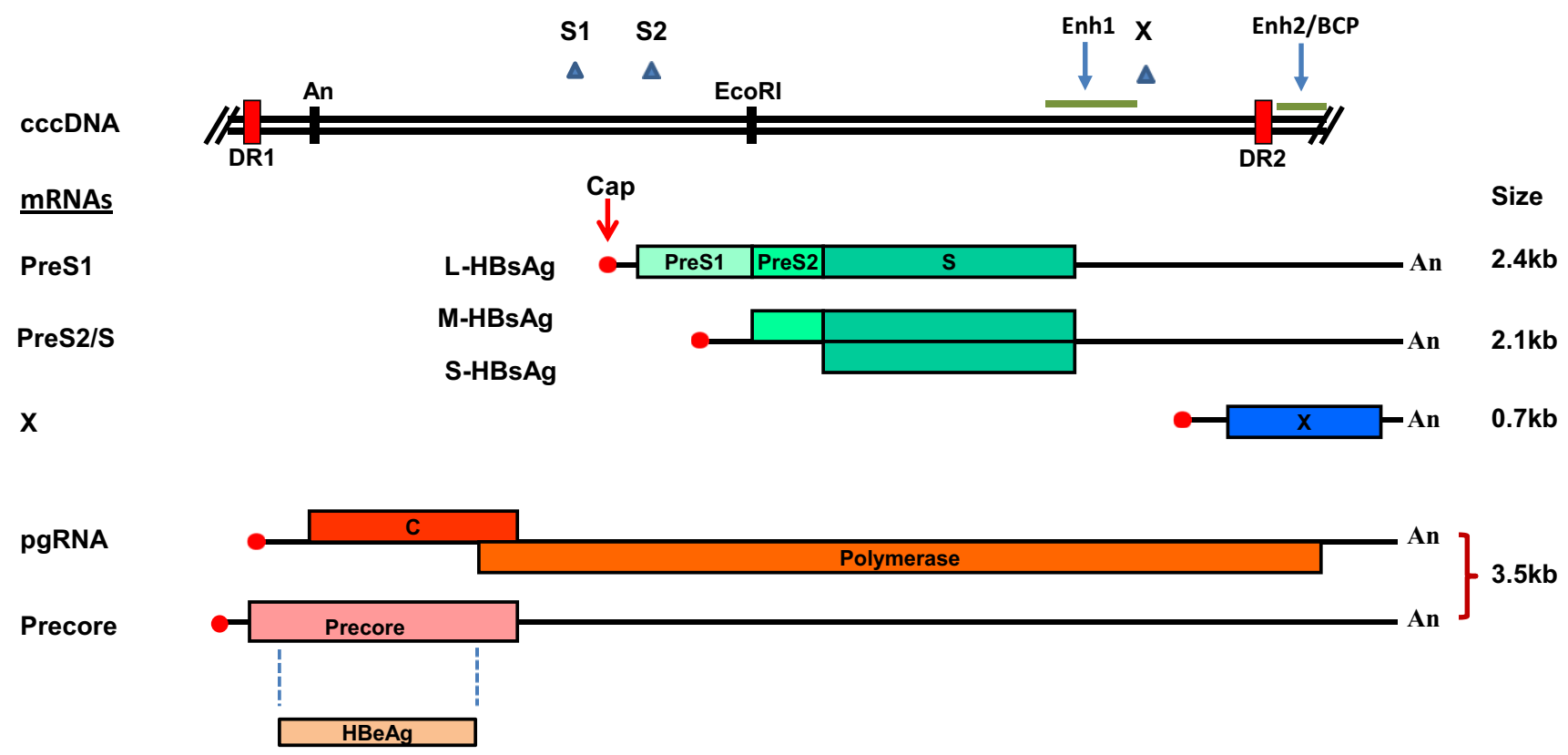

Fig. 1 The cccDNA, depicted here in linear outline, is the transcriptionally active form of HBV. The enhancers and promoters involved in transcript synthesis are also shown as are the transcripts themselves, the ORFs which they contain and the proteins which

The core promoter is responsible for the synthesis of two longer than genome length mRNAs $(3.5 \mathrm{~kb})$ which differ with respect to the start of their $5^{\prime}$ end. The longer of the two by a small number of ribonucleotides is the precore mRNA containing the initiation codon for synthesis of the precore protein, which is the precursor for hepatitis $\mathrm{B}$ e antigen ( $\mathrm{HBeAg})$. The protein undergoes proteolytic processing at its $\mathrm{N}$-terminus for the removal of a signal peptide of 19 amino-acids in length, which targets the protein to the $\mathrm{ER}$, and a furin cleavage for the removal of an arginine rich domain at its C-terminus [31-33]. What is left is the $15-\mathrm{kD}$ $\mathrm{HBeAg}$ which is secreted and dispensable protein for replication that appears to act as a tolerogen in newborns and chronic infection [34]. The other transcript is the pregenomic RNA (pgRNA) which is bicistronic in nature and encodes for the core $(21 \mathrm{kD})$ or hepatitis B core antigen $(\mathrm{HBcAg})$ and the polymerase $(90 \mathrm{kD})$ proteins. The pgRNA in addition constitutes the template for reverse transcription during the replication of the viral genome, as explained below. The core has the capacity to dimerise and form nucleocapsids by self-assembly consisting of 240 copies (120 dimers) of the protein [35], while the polymerase is a multifunctional protein which acts as a reverse transcriptase (rt), as DNA polymerase and has RNase $\mathrm{H}$ activity also [36]. Regulation of production of these two proteins is such as to favour the generation of the numbers mentioned above of core molecules required for nucleocapsid formation per single molecule of polymerase packaged with the pgRNA. they encode, their lengths and their co-terminal nature at a common polyadenylation signal (An). Modified from Baltayiannis and Karayiannis [28]

The Pre-S/S ORF of the genome encodes for the three envelope glycoproteins produced by differential initiation of translation at each of three in-frame initiation codons. These are known as the large (L), middle (M) and small (S) HBsAgs, with the latter being the more abundant constituent of the viral envelope. Two transcripts of 2.4 and $2.1 \mathrm{~kb}$ are involved, the synthesis of which is controlled by the S1 and S2 promoters respectively. L-HBsAg is translated from the $2.4 \mathrm{~kb}$ transcript while the $\mathrm{M}$ - and $\mathrm{S}$-HBsAgs are translated from the $2.1 \mathrm{~kb}$ transcript, the latter through leaky ribosome scanning. The S-HBsAg is thus the smallest of the three co-terminal proteins and its 226 amino-acids are shared by the other two at their $\mathrm{C}$-terminus. The $\mathrm{M}$ protein has an additional 55 aminoacids at its N-terminus encoded by the Pre-S2 region, while the $\mathrm{L}$ protein includes in addition another 107-118 aminoacids (depending on genotype) from the Pre-S1 region [29]. The first $48 \mathrm{~N}$-terminal amino-acids of Pre-S1, as originally thought (see later), contain the region responsible for attachment of the virus to its hepatocyte receptor [37, 38]. Moreover, myristylation of L-HBsAg appears to be essential for infectivity [39]. All three proteins are glycosylated while the $\mathrm{L}$ and $\mathrm{S}$ proteins may also be present in an unglycosylated form in particles. They are synthesised at the ER and maintain a transmembrane configuration that enables budding of the virus through the ER during maturation [40].

The envelopes of the Dane particles and of the two types of sub-viral particles contain all three HBsAgs, but their 
relative ratios are not identical. The $\mathrm{S}$ protein represents the majority in Dane particles with equal amounts of the $\mathrm{M}$ and $\mathrm{L}$ proteins, whereas the spheres contain mainly $\mathrm{S}$ and $\mathrm{M}$ proteins, with trace amounts of the $\mathrm{L}$ protein. Filaments have S-HBsAg as the majority protein with $\mathrm{M}$ and $\mathrm{L}$ proteins being present in equal amounts, which, however, are not as high as those in the Dane particle [41].

The fourth and smallest ORF encodes for the $17 \mathrm{kD}$ HBx protein which is translated from the shortest transcript of $0.7 \mathrm{~kb}$ in length. It consists of 154 amino-acids and appears to modulate host-cell signal transduction, acts as a gene transactivator under experimental conditions, can activate transcription factors and therefore is implicated in binding the covalent closed circular DNA (cccDNA) minichromosome (reviewed in $[42,43]$ ).

\section{Viral life cycle}

\section{Attachment}

It is now clear that species-specificity and hepatotropism are determined by the requirement of transcription factors enriched in hepatocytes as mentioned above and the expression on human hepatocyte cells of the recently described sodium taurocholate co-transporting peptide (NTCP) which constitutes the HBV receptor (Fig. 2a, [44]). NTCP is a bile acid transporter expressed at the basolateral membrane of hepatocytes. The receptor binds the N-terminal end of L-HBsAg as described above, and in fact the region involved may include the first 75 aminoacids [45]. In addition, subsequent studies have indicated that heparin sulfate proteoglycans may be involved in the initial stages of binding [46], as well as glypican 5 [47], thus suggesting co-operative binding in the process of attachment and uptake.

\section{Penetration and uncoating}

Evidence suggests that, following binding, the virion is internalised through clathrin-mediated endocytosis [48]. However, information on the removal of the viral envelope and the trafficking of the nucleocapsid to the nuclear pores is still lacking. Transport factors such as importin alpha and beta and component nucleoporin 153 ensure nucleocapsid delivery to the nuclear basket $[49,50]$. Disassembly of nucleocapsids ensues leading to the release into the nucleoplasm of the rcDNA genome of the virus with its covalently attached polymerase.

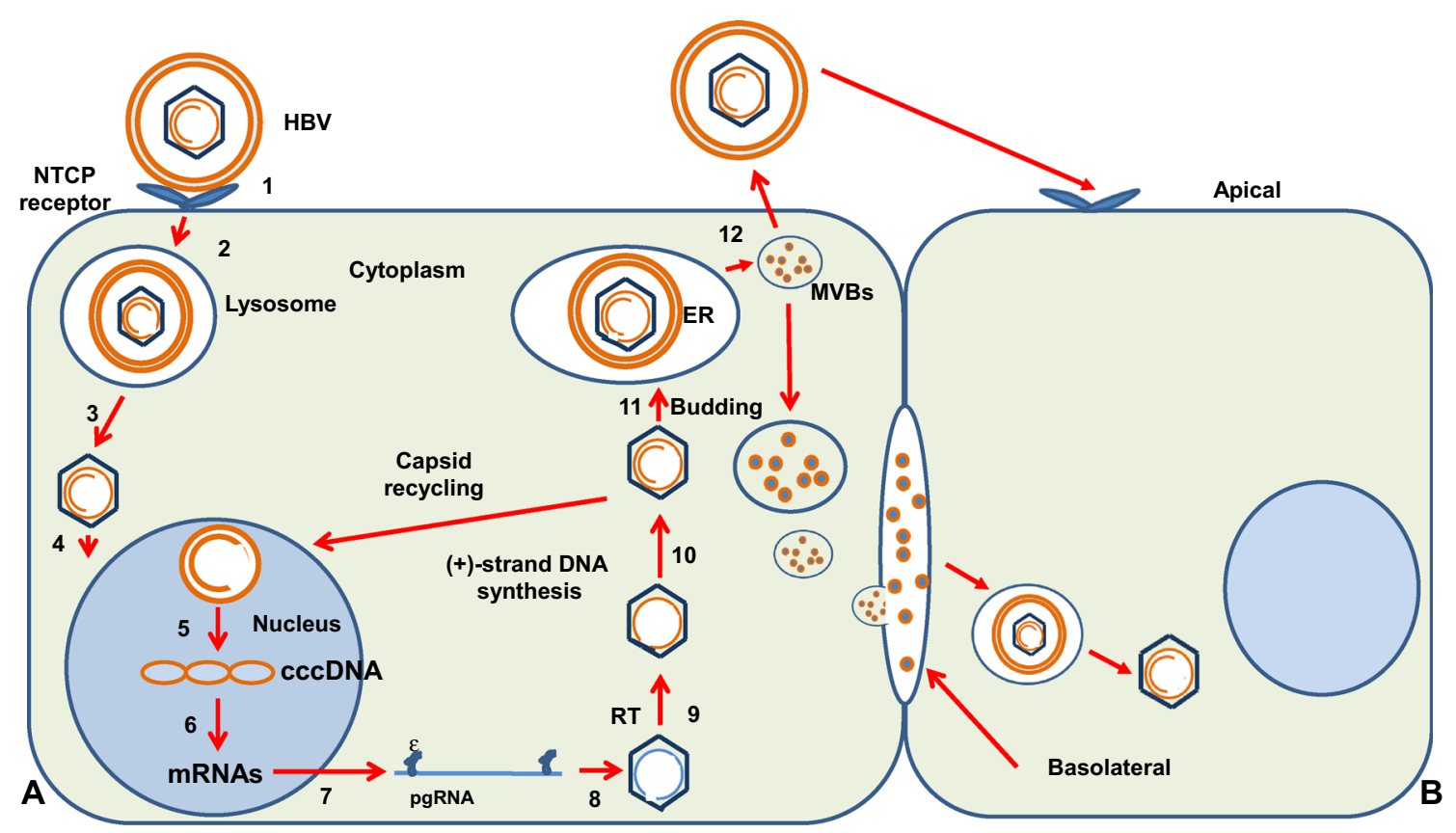

Fig. 2 Diagrammatic representation of hepatocyte infection with HBV. a The various stages of the life cycle of the virus from attachment to release, as explained in the text and numbered as: 1 attachment; 2 endocytosis; 3 capsid release; 4 rcDNA entry into the nucleus; 5 cccDNA synthesis; 6 transcription; 7 mRNA transfer to the cytoplasm; 8 encapsidation; 9 (-)-DNA strand synthesis by reverse transcription; $10(+)$-DNA strand synthesis; 11 budding of virions into the ER lumen; 12 virus release through multivesicular body (MVB) transfer to hepatocyte surface. b Basolateral release of the virus for cell-to-cell spread. Part modified from Baltayiannis and Karayiannis [28] 


\section{Transcription/translation}

The rcDNA is converted into the cccDNA form in a process involving a number of stages whereby the viral polymerase covalently attached to the $5^{\prime}$ end of the negative (-)-DNA strand and the short RNA oligomer from the $5^{\prime}$ end of the positive (+)-DNA strand which is used to prime (+)-DNA strand synthesis are removed, the variable positive strand is completed and finally the ends of the two now complete strands are ligated together [29, 51]. This process likely involves the use of specific cellular factors that are presently unknown. In this form, cccDNA is quite stable and behaves as a minichromosome. Moreover, a number of epigenetic factors which are recruited onto the cccDNA, such as histones $\mathrm{H} 3$ and $\mathrm{H} 4$, transcription factors that include CREB, ATF, STAT1 and STAT2, chromatinmodifying enzymes, histone acetyltransferases and deacetylases, and the $\mathrm{HBc}$ and $\mathrm{HBx}$ proteins [52-54] appear to modulate cccDNA transcriptional activity. Thus, the cccDNA constitutes the template for viral transcript synthesis by the host RNA polymerase II. The synthesised transcripts are then exported to the cytoplasm where they are translated into the various viral proteins described above.

\section{Encapsidation}

The pgRNA, in addition to being the transcript for core and polymerase synthesis, also serves as the template for DNA synthesis by reverse transcription in the first instance. Being longer than genome length, it has a terminal redundancy which is the result of readthrough, passing the start of the transcript synthesis by about $120 \mathrm{nt}$, terminating with the poly-A tail. This redundancy contains a second copy each of the direct repeat 1 (DR1) and the encapsidation signal $\varepsilon$, a secondary RNA structure that encompasses the precore nucleotide sequence $[55,56]$.

Encapsidation of the pgRNA into the nucleocapsid is the next step in the virus life cycle and involves a series of events employing both viral and host factors. The polymerase has three functional domains, each one of which is in turn involved in DNA priming (terminal protein), reverse transcription (rt) and pgRNA degradation (RNAse $\mathrm{H})$. The terminal protein is separated from the rt domain by a spacer region of unknown function. The polymerase engages the $\varepsilon$ at the $5^{\prime}$ end of the pgRNA, a process that triggers encapsidation of the complex by the core protein (Fig. 3). It appears that the cap structure is also involved in this process [58], as well as eIF4E and heat shock proteins, which are thought to be instrumental in aiding encapsidation, stabilisation and activation of the polymerase [59, 60]. The C-terminus of the core protein, which as mentioned before is arginine-rich and in addition certain of its amino- acids are phosphorylated, is involved in pgRNA binding thus facilitating encapsidation. The core is also involved in reverse transcription initiation, nucleocapsid envelopment and fulfils other roles, as recently reviewed [61].

The subsequent steps in virus nucleic acid synthesis then take place within the nucleocapsid. The $\varepsilon$ encapsidation structure consists of a lower stem, an upper stem, a side bulge and an apical loop, formed through base pairing of palindromic nucleotide sequences. Part of the side bulge of $\varepsilon$ serves as a template for the synthesis of a 4-nucleotide-long DNA primer [62], covalently attached to the terminal protein domain of the polymerase through a phosphodiester linkage between dTTP and the hydroxyl group of a tyrosine residue in the terminal protein (position 63) [63, 64]. The polymeraseprimer complex next translocates to the $5^{\prime}$ of the pgRNA, where it hybridises with part of the DR1 region with which the primer is homologous. This translocation event to the correct site, i.e. DR1 at the $3^{\prime}$ end of the pgRNA, is likely assisted by two other elements, $\phi$ and $\omega$ (Fig. 3), which interact with $\varepsilon$ $[65,66]$. (-)-DNA strand synthesis is thus initiated by reverse transcription as the complex advances towards the $5^{\prime}$ end of the pgRNA, having a terminal redundancy of about 10 nucleotides. The RNA template is concurrently degraded by the RNAse $\mathrm{H}$ activity of the polymerase, except for the final 11-16 or so ribonucleotides which encompass the DR1 region of the $5^{\prime}$ of the pgRNA. This ribonucleotide fragment serves as the primer for (+)-DNA strand synthesis [67]. It hybridises with the homologous to it DR2 at the $5^{\prime}$ end of the newly synthesised (-)-DNA strand necessitating a second translocation event. (+)-DNA strand synthesis then proceeds to the $5^{\prime}$ end of the (-)-DNA strand. Circularisation facilitated by the short terminal redundancy of the (-)-DNA strand allows template exchange and continuation of (+)-DNA strand synthesis along the $3^{\prime}$ end of the (-)-DNA strand [68]. Synthesis of both DNA strands occurs within the nucleocapsid and this is facilitated through pores in the capsid that allow passage of nucleotides. However, once the maturing nucleocapsid is enveloped by budding through the endoplasmic reticulum membrane, the nucleotide pool within the capsid is depleted leaving an incomplete (+)-DNA strand, hence the partially double stranded nature of the HBV genome [69].

\section{Maturation}

Mature nucleocapsids, meaning that they contain the newly synthesised partially double-stranded rcDNA with the polymerase still bound to the $5^{\prime}$ end of the (-)-DNA strand, can follow one of two pathways. Early on infection and until sufficient amounts of HBsAg accumulate, nucleocapsids are shuttled back to the nucleus in order to replenish the cccDNA pool $[52,70]$. In the final stages of morphogenesis, virions bud through the ER membrane where HBsAg proteins are already localised into the lumen, 


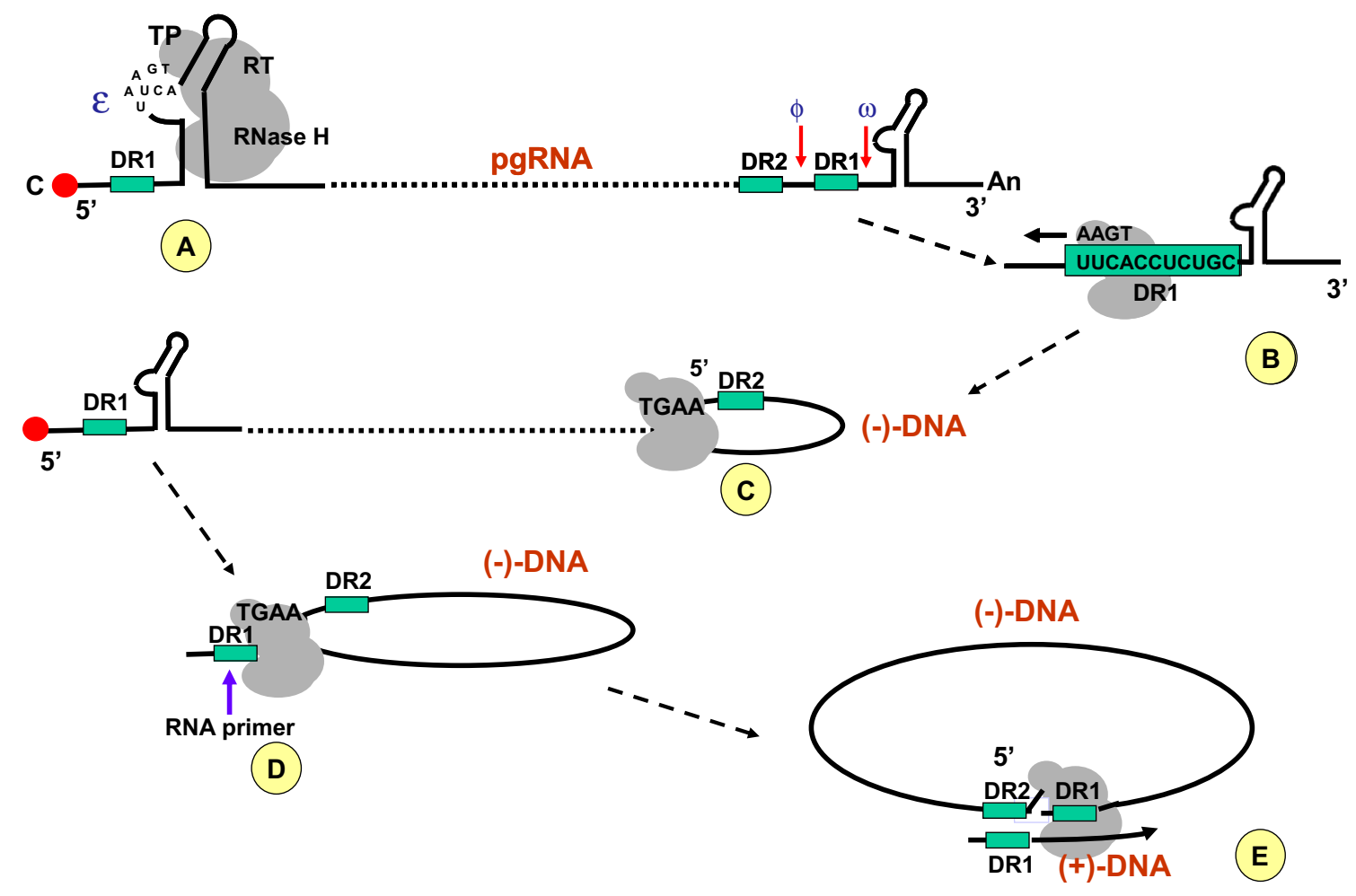

Fig. 3 Replication strategy of HBV. a Primer synthesis; b translocation and binding to DR1; c synthesis of the (-)-DNA strand with concurrent degradation of the pgRNA; d circularisation of the (-)DNA strand though covalent attachment of the polymerase at its $5^{\prime}$

acquiring in the process their outer envelope [71]. A crucial determinant of these processes is the topology and conformational arrangement of L-HBsAg. Studies have established that about half of the protein lies with its $\mathrm{N}$-terminus on the cytosolic side of the ER, whence it favors binding to the nucleocapsid and therefore budding. L-HBsAg with its terminus in the lumen allows its exposure on the surface of the virion and therefore easy access to the NTCP receptor during binding to hepatocytes [41]

\section{Egress}

It was generally assumed that, as HBsAg proteins accumulate in the ER-Golgi intermediate compartment, virions will accumulate in the lumen and follow the secretory pathway during cell exit, akin to the route that SVPs follow. It is now known that virions exit by using a different pathway which relies on proteins associated with the endosomal sorting complex required for transport, which form multivesicular bodies [72].

\section{Infection through cell-to-cell spread}

The life cycle described above is initiated following receptor-mediated attachment of a cell-free virus which end and preservation of the RNA primer (DR1) from the $5^{\prime}$ end of the pgRNA; e hybridisation of the DR1 RNA primer with DR2 at the $5^{\prime}$ end of the (-)-DNA strand and extension for (+)-DNA strand synthesis. Modified from Karayiannis [57]

moves from the sinusoidal lumen filled with blood into the Space of Disse. In view of the large size of the liver, the mode of viral spread must be efficient and of course dependent on the size of the inoculum, both of which determine the length of the incubation period. Clusters of virus-infected cells are frequently observed following immunohistochemical staining of liver sections from patients and experimentally infected animals [73]. Such observations suggest that HBV may also spread through cell-to-cell infection. Thus, movement of infectious virions to remotely situated hepatocytes possible only through their secretion into the extracellular milieu may not be the only means of virus spread.

It is generally accepted that HBV is not directly cytopathic, but that the histological pathology observed is the result of activation of the adaptive immune response and, in particular, the production of virus specific cytotoxic T-cells [74-76]. Lysis of infected hepatocytes evident by a rise in transaminase levels during acute infection or persistently raised levels in chronic infection entails their replacement through regeneration. Hepatocytes although terminally differentiated retain their capacity for substantial proliferation in response to liver injury. Their normal lifespan is longer than 6 months [77]. Replacement of lost hepatocytes may also occur through stem cell 
differentiation, as these cells may be resident in the region of portal tracts [78]. These events allow the liver to maintain its mass, but at the same time have implications when one considers which determinants are needed which facilitate cell-to-cell spread of HBV.

As described above, chronic HBV infection is maintained by the presence of the cccDNA minichomosome which persists throughout the lifespan of the infected hepatocyte. During liver regeneration as a result of immune-mediated hepatocyte lysis and hepatocyte proliferation to compensate for this, cell division may result in cccDNA decline and generation of cccDNA-free cells. Indeed, a recent study using the urokinase-type plasminogen activator/severe combined immune-deficiency mouse model with transplanted tupaia hepatocytes infected with woolly monkey HBV, indicated that, although there was increased hepatocyte proliferation, this was accompanied by a $75 \%$ reduction in virion production, as well as reduced pgRNA synthesis and core protein production [79]. It appears therefore, that during cell division, the cccDNA pool is reduced through loss of cccDNA, and that only a fraction of daughter cells carry cccDNA. Therefore, this mechanism only accounts for limited cell-to-cell spread of infection.

Cell-to-cell spread employed by other viruses often involves complex inter-cellular adhesion and is safeguarded by the presence of the appropriate receptors; cellular polarity which determines whether virus is released into the extracellular compartment or basolaterally may contribute to pathogenicity, and finally intra-cellular trafficking (Fig. 2b, [80]). What is more, cell-to-cell spread is favored by viruses which are released from the infected cell through budding from the cell membrane or use an exocytic route such as that of multivesicular bodies described above for hepadnaviruses. This mode of virus spread/transmission avoids immune attack, in particular antibody-mediated blocking of receptor binding. In the case of $\mathrm{HBV}$, experimental evidence suggests that cell-tocell spread is favored by polarised release of virions [73, 81]. In fact, hepatocytes traffic and export $\mathrm{HBV}$ basolaterally by polarity-dependent mechanisms, which in the case of DHBV is associated with sphingolipid structures [82].

Exosomes are extracellular vesicles that originate from multivesicular bodies, 40-150 $\mathrm{nm}$ in diameter, which are produced by most cell types. They have been implicated in a number of processes, and, following their secretion into the extracellular space, they can mediate indirect cell-tocell communication through the transfer of macromolecules, miRNAs and other RNAs, but also viruses [83]. Cell-to-cell spread of hepatitis $\mathrm{C}$ virus is well documented [84] and, indeed, exosomes appear to transmit the virus to hepatocytes in a receptor-independent manner [85].
The impact of cell-to-cell spread in HBV infection and persistence are not well understood at all. However, mathematical modelling has recently been employed in an attempt to shed light on these events and study the effect on outcome following potential actions by the immune system that can result in clearance, non-clearance or fulminant hepatitis of acute HBV infection. Cell-to-cell transmission, although not impacting establishment of infection, it appeared to hinder its clearance and suggested that it might be a factor in causing fulminant hepatitis. The model showed that it is the combination of cell-to-cell transmission strength, cytokine production and the $\mathrm{T}$ cell clearance number that decides the fate of HBV acute infection [86]. Clearly, further work is needed to shed more light on the mechanisms involved in cell-to-cell spread of HBV.

\section{Concluding remarks}

Our knowledge with regards to the replication strategy of $\mathrm{HBV}$ and its life cycle in general has increased significantly in recent years. There are still, however, missing pieces in this jigsaw, the completion of which requires a reliable and as near authentic as possible in vitro model of HBV infection. This will allow the finer dissection of the various steps involved in the replication process of the virus described above, the interactions of the polymerase itself with the pgRNA template initially and subsequent DNA strand synthesis. Moreover, the successful expression of the polymerase by recombinant DNA technology and its crystallisation will allow studies on its multifunctional role and active conformation during replication, all of which may reveal possible targets for future antiviral design. Finally, such cell culture systems will elucidate and map in greater detail the steps involved in cell-to-cell spread of the virus.

\section{Compliance with ethical standards}

Conflict of interest P. Karayiannis has no conflicts of interest.

Human rights No research involving human participants and/or animals.

\section{References}

1. WHO factsheet no. 204. http://www.who.int/mediacentre/fact sheets/fs204/en/. Accessed 14 June 2017

2. El-Serag HB. Epidemiology of viral hepatitis and hepatocellular carcinoma. Gastroenterology 2012;142:1264-1273

3. Lozano R, Naghavi M, Foreman K, Lim S, Shibuya K, Aboyans $\mathrm{V}$, et al. Global and regional mortality from 235 causes of death for 20 age groups in 1990 and 2010: a systematic analysis for the Global Burden of Disease Study 2010. Lancet 2012;380:2095-2128 
4. Krugman S, Giles JP, Hammond J. Infectious hepatitis. Evidence for two distinctive clinical, epidemiological, and immunological types of infection. JAMA 1967;200:365-373

5. Giles JP, McCollum RW, Berndtson LW Jr, Krugman S. Relation of Australia-SH antigen to the willowbrook MS-2 strain. N Engl J Med 1969;281:119-122

6. Blumberg BS, Alter HJ, Visnich S. A "new" antigen in leukemia sera. JAMA 1965;191:541-546

7. Bayer ME, Blumberg BS, Werner B. Particles associated with Australia antigen in the sera of patients with leukaemia. Down's Syndrome and hepatitis. Nature 1968;218:1057-1059

8. Prince AM. Detection of serum hepatitis virus carriers by testing for the SH (Australia) antigen. A review of current methodology. Vox Sang 1970;19:417-424

9. Dane DS, Cameron CH, Briggs M. Virus-like particles in serum of patients with Australia-antigen-associated hepatitis. Lancet 1970;1:695-698

10. Robinson WS. DNA and DNA polymerase in the core of the Dane particle of hepatitis B. Am J Med Sci 1975;270:151-159

11. Robinson WS, Lutwick LI. The virus of hepatitis, type B (first of two parts). N Engl J Med 1976;295:1168-1175

12. Robinson WS, Lutwick LI. The virus of hepatitis, type B. (Second of two parts). N Engl J Med 1976;295:1232-1236

13. Beasley RP, Hwang LY, Lin CC, Chien CS. Hepatocellular carcinoma and hepatitis B virus. A prospective study of 22707 men in Taiwan. Lancet 1981;2:1129-1133

14. Szmuness W, Stevens CE, Zang EA, Harley EJ, Kellner A. A controlled clinical trial of the efficacy of the hepatitis B vaccine (Heptavax B): a final report. Hepatology 1981;1:377-385

15. Karayiannis $\mathrm{P}$, Main J, Thomas HC. Hepatitis vaccines. Br Med Bull 2004;70:29-49

16. Lok AS, McMahon BJ, Brown RS Jr, Wong JB, Ahmed AT, Farah W et al. Antiviral therapy for chronic hepatitis B viral infection in adults: a systematic review and meta-analysis. Hepatology 2016;63:284-306

17. Zoulim F, Lebossé F, Levrero M. Current treatments for chronic hepatitis B virus infections. Curr Opin Virol 2016;18:109-116

18. Locarnini SA, Roggendorf M. Other hepadnaviridae [Avihepadnaviridae (DHBV) and Orthohepadnaviridae (WHV)]. In: Thomas HC, Lok ASF, Locarnini SA, Zuckerman AJ, editors. Viral Hepatitis. 4th ed. Wiley-Blackwell: Oxford; 2014. p. 96-106

19. Kramvis A. Genotypes and genetic variability of hepatitis B virus. Intervirology 2014;57:141-150

20. Tran TT, Trinh TN, Abe K. New complex recombinant genotype of hepatitis B virus identified in Vietnam. J Virol 2008;82:5657-5663

21. Tatematsu K, Tanaka Y, Kurbanov F, Sugauchi F, Mano S, Maeshiro T et al. A genetic variant of hepatitis B virus divergent from known human and ape genotypes isolated from a Japanese patient and provisionally assigned to new genotype J. J Virol 2009;83:10538-10547

22. Pourkarim MR, Amini-Bavil-Olyaee S, Kurbanov F, Van Ranst M, Tacke F. Molecular identification of hepatitis B virus genotypes/subgenotypes: revised classification hurdles and updated resolutions. World J Gastroenterol 2014;20:7152-7168

23. Araujo NM. Hepatitis B virus intergenotypic recombinants worldwide: an overview. Infect Genet Evol 2015;36:500-510

24. Ganem D, Prince AM. Hepatitis B virus infection-natural history and clinical consequences. N Engl J Med 2004;350:1118-1129

25. Kaplan PM, Greenman RL, Gerin JL, Purcell RH, Robinson WS. DNA polymerase associated with human hepatitis B antigen. J Virol 1973;12:995-1005

26. Robinson WS, Clayton DA, Greenman RL. DNA of a human hepatitis B virus candidate. J Virol 1974;14:384-391

27. Summers J, O'Connell A, Millman I. Genome of hepatitis B virus: restriction enzyme cleavage and structure of DNA extracted from Dane particles. Proc Natl Acad Sci USA 1975;72:4597-4601

28. Baltayiannis G, Karayiannis P. Treatment options beyond IFN $\alpha$ and NUCs for chronic HBV infection: expectations for tomorrow. J Viral Hepatol 2014;21:753-761

29. Seeger C, Mason WS. Hepatitis B virus biology. Microbiol Mol Biol Rev 2000;4:51-68

30. Quasdorff M, Protzer U. Control of hepatitis B virus at the level of transcription. J Viral Hepatol 2010;17:527-536

31. Wang J, Lee AS, Ou JH. Proteolytic conversion of hepatitis B virus e antigen precursor to end product occurs in a postendoplasmic reticulum compartment. J Virol 1991;65:5080-5083

32. Messageot F, Salhi S, Eon P, Rossignol JM. Proteolytic processing of the hepatitis B virus e antigen precursor. Cleavage at two furin consensus sequences. J Biol Chem 2003;278:891-895

33. Ito K, Kim KH, Lok AS, Tong S. Characterization of genotypespecific carboxyl-terminal cleavage sites of hepatitis B virus e antigen precursor and identification of furin as the candidate enzyme. J Virol 2009;83:3507-3517

34. Milich DR, Jones JE, Hughes JL, Price J, Raney AK, McLachlan A. Is a function of the secreted hepatitis $B$ e antigen to induce immunologic tolerance in utero? Proc Natl Acad Sci USA 1990;87:6599-6603

35. Crowther RA, Kiselev NA, Bottcher B, Berriman JA, Borisova GP, Ose V, Pumpens P. Three-dimensional structure of hepatitis $\mathrm{B}$ virus core particles determined by electron cryomicroscopy. Cell 1994;77:943-950

36. Ganem D, Schneider RJ. Hepadnaviridae: the viruses and their replication. In: Knipe DM, Howley PM, editors. Fields virology, vol. 2. 4th ed. Philadelphia: Lippincott Williams \& Wilkins; 2001. p. 2923-2969

37. Neurath AR, Kent SB, Strick N, Parker K. Identification and chemical synthesis of a host cell receptor binding site on hepatitis B virus. Cell 1986;46:429-436

38. Gripon P, Cannie I, Urban S. Efficient inhibition of hepatitis B virus infection by acylated peptides derived from the large viral surface protein. J Virol 2005;79:1613-1622

39. Gripon P, Le Seyec J, Rumin S, Guguen-Guillouzo C. Myristylation of the hepatitis B virus large surface protein is essential for viral infectivity. Virology 1995;213:292-299

40. Eble BE, MacRae DR, Lingappa VR, Ganem D. Multiple topogenic sequences determine the transmembrane orientation of the hepatitis B surface antigen. Mol Cell Biol 1987;7:3591-35601

41. Bruss V. Hepatitis B virus morphogenesis. World J Gastroenterol 2007; 13:65-73

42. Slagle BL, Bouchard MJ. Hepatitis B Virus X and Regulation of Viral Gene Expression. Cold Spring Harb Perspect Med 2016;6:a021402

43. Geng M, Xin X, Bi LQ, Zhou LT, Liu XH. Molecular mechanism of hepatitis B virus $X$ protein function in hepatocarcinogenesis. World J Gastroenterol 2015;21:10732-10738

44. Yan H, Zhong G, Xu G, He W, Jing Z, Gao Z et al.. Sodium taurocholate cotransporting polypeptide is a functional receptor for human hepatitis B and D virus. eLife 2012;1:e0049

45. Blanchet M, Sureau C. Infectivity determinants of the hepatitis B virus pre-S domain are confined to the N-terminal 75 amino acid residues. J Virol 2007;81:5841-5849

46. Schulze A, Gripon P, Urban S. Hepatitis B virus infection initiates with a large surface protein-dependent binding to heparan sulfate proteoglycans. Hepatology 2007;46:1759-1768

47. Verrier ER, Colpitts CC, Bach C, Heydmann L, Weiss A, Renaud $\mathrm{M}$ et al. A targeted functional RNA interference screen uncovers glypican 5 as an entry factor for hepatitis B and D viruses. Hepatology 2016;63:35-48 
48. Huang HC, Chen CC, Chang WC, Tao MH, Huang C. Entry of hepatitis B virus into immortalized human primary hepatocytes by clathrin-dependent endocytosis. J Virol 2012;86:9443-9453

49. Rabe B, Delaleau M, Bischof A, Foss M, Sominskaya I, Pumpens $\mathrm{P}$ et al. Nuclear entry of hepatitis B virus capsids involves disintegration to protein dimers followed by nuclear reassociation to capsids. PLoS Pathog 2009;5:e1000563

50. Schmitz A, Schwarz A, Foss M, Zhou L, Rabe B, Hoellenriegel J et al. Nucleoporin 153 arrests the nuclear import of hepatitis B virus capsids in the nuclear basket. PLoS Pathog 2010;6:e1000741

51. Tuttleman JS, Pourcel C, Summers J. Formation of the pool of covalently closed circular viral DNA in hepadnavirus-infected cells. Cell 1986;47:451-460

52. Pollicino T, Belloni L, Raffa G, Pediconi N, Squadrito G, Raimondo $G$, Levrero $M$. Hepatitis $B$ virus replication is regulated by the acetylation status of hepatitis B virus cccDNA-bound $\mathrm{H} 3$ and $\mathrm{H} 4$ histones. Gastroenterology 2006;130:823-837

53. Belloni L, Pollicino T, Cimino L, Raffa G, Raimondo G, Levrero M. Nuclear HBx binds in vivo on the HBV minichromosome, modifies the epigenetic regulation of ccc-DNA function and potentiates HBV replication. J Hepatol 2008;48:s25

54. Koumbi L, Karayiannis P. The epigenetic control of hepatitis B virus modulates the outcome of infection. Front ${ }^{-}$Microbiol 2016;6:1491

55. Kramvis A, Kew MC. Structure and function of the encapsidation signal of hepadnaviridae. J Viral Hepat 1998;5:357-367

56. Summers J, Mason WS. Replication of the genome of a hepatitis B-like virus by reverse transcription of an RNA intermediate. Cell 1982;29:403-415

57. Karayiannis P. Hepatitis B virus: old, new and future approaches to antiviral treatment. J Antimicrob Chemother 2003;51:761-785

58. Jeong JK, Yoon GS, Ryu WS. Evidence that the 5'-end cap structure is essential for encapsidation of hepatitis B virus pregenomic RNA. J Virol 2000;74(12):5502-5508

59. Kim S, Wang H, Ryu WS. Incorporation of eukaryotic translation initiation factor eIF4E into viral nucleocapsids via interaction with hepatitis B virus polymerase. J Virol 2010;84:52-58

60. Hu J, Toft DO, Seeger C. Hepadnavirus assembly and reverse transcription require a multi-component chaperone complex which is incorporated into nucleocapsids. EMBO J 1997;16:59-68

61. Zlotnick A, Venkatakrishnan B, Tan Z, Lewellyn E, Turner W, Francis S. Core protein: a pleiotropic keystone in the HBV lifecycle. Antiviral Res 2015;121:82-93

62. Nassal M, Rieger A. A bulged region of the hepatitis B virus RNA encapsidation signal contains the replication origin for discontinuous first-strand DNA synthesis. J Virol 1996; 70:2764-2773

63. Zoulim F, Seeger C. Reverse transcription in hepatitis B viruses is primed by a tyrosine residue of the polymerase. J Virol 1994;68:6-13

64. Weber M, Bronsema V, Bartos H, Bosserhoff A, Bartenschlager $\mathrm{R}$, Schaller $\mathrm{H}$. Hepadnavirus $\mathrm{P}$ protein utilizes a tyrosine residue in the TP domain to prime reverse transcription. J Virol 1994;68:2994-2999

65. Tang H, McLachlan A. A pregenomic RNA sequence adjacent to DR1 and complementary to epsilon influences hepatitis B virus replication efficiency. Virology 2002;303:199-210

66. Abraham TM, Loeb DD. Base pairing between the $5^{\prime}$ half of epsilon and a cis-acting sequence, phi, makes a contribution to the synthesis of minus-strand DNA for human hepatitis B virus. J Virol 2006;80:4380-4387
67. Haines KM, Loeb DD. The sequence of the RNA primer and the DNA template influence the initiation of plus-strand DNA synthesis of hepatitis B virus. J Mol Biol 2007;370:471-480

68. Lewellyn EB, Loeb DD. Base pairing between cis-acting sequences contributes to template switching during plus-strand DNA synthesis in human hepatitis $\mathrm{B}$ virus. J Virol 2007;81:6207-6215

69. Nassal M. Hepatitis B viruses: reverse transcription a different way. Virus Res 2008;134:235-249

70. Lentz TB, Loeb DD. Roles of the envelope proteins in the amplification of covalently closed circular DNA and completion of synthesis of the plus-strand DNA in hepatitis B virus. J Virol 2011;85:11916-11927

71. Gerelsaikhan T, Tavis JE, Bruss V. Hepatitis B virus nucleocapsid envelopment does not occur without genomic DNA synthesis. J Virol 1996;70:4269-4272

72. Watanabe T, Sorensen EM, Naito A, Schott M, Kim S, Ahlquist P. Involvement of host cellular multivesicular body functions in hepatitis B virus budding. Proc Natl Acad Sci USA 2007; 104:10205-10210

73. Jilbert AR, Freiman JS, Burrell CJ, Holmes M, Gowans EJ, Rowland R, Hall P, Cossart YE. Virus-liver cell interactions in duck hepatitis B virus infection. A study of virus dissemination within the liver. Gastroenterology 1988;95:1375-1282

74. Bertoletti A, Gehring AJ. The immune response during hepatitis B virus infection. J Gen Virol 2006;87:1439-1449

75. Maini MK, Boni C, Lee CK, Larrubia JR, Reignat S, Ogg GS et al. The role of virus-specific CD8(+) cells in liver damage and viral control during persistent hepatitis B virus infection. J Exp Med 2000;191:1269-1280

76. Thimme R, Wieland S, Steiger C, Ghrayeb J, Reimann KA, Purcell RH et al. CD8(+) T cells mediate viral clearance and disease pathogenesis during acute hepatitis B virus infection. J Virol 2003;77:68-76

77. MacDonald RA. "Lifespan" of liver cells. Arch Intern Med 1960; 107:335-343

78. Thorgeirsson SS. Hepatic stem cells in liver regeneration. FASEB J 1996;10:1249-1256

79. Lutgehetmann M, Volz T, Köpke A, Broja T, Tigges E, Lohse $\mathrm{AW}$ et al. In vivo proliferation of hepadnavirus-infected hepatocytes induces loss of covalently closed circular DNA in mice. Hepatology 2010;52:16-24

80. Sattentau Q. Avoiding the void: cell-to-cell spread of human viruses. Nat Rev Microbiol 2008;6:815-826

81. Funk A, Hohenberg H, Mhamdi M, Will H, Sirma H. Spread of hepatitis $\mathrm{B}$ viruses in vitro requires extracellular progeny and may be codetermined by polarized egress. J Virol 2004;78:3977-3983

82. Bhat P, Snooks MJ, Anderson DA. Hepatocytes traffic and export hepatitis B virus basolaterally by polarity-dependent mechanisms. J Virol 2011;85:12474-12481

83. Lee Y, El Andaloussi S, Wood MJ. Exosomes and microvesicles: extracellular vesicles for genetic information transfer and gene therapy. Hum Mol Genet 2012;21:R125-R134

84. Timpe JM, Stamataki Z, Jennings A, Hu K, Farquhar MJ, et al. Hepatitis $\mathrm{C}$ virus cell-cell transmission in hepatoma cells in the presence of neutralising antibodies. Hepatology 2008;47:17-24

85. Bukong TN, Momen-Heravi F, Kodys K, Bala S, Szabo G. Exosomes from hepatitis $\mathrm{C}$ infected patients transmit $\mathrm{HCV}$ infection and contain replication competent viral RNA in complex with Ago2-miR122-HSP90. PLoS Pathog 2014;10:e1004424

86. Goyal A, Murray JM. Modelling the impact of cell-to-cell transmission in hepatitis B virus. PLoS One 2016;11:e0161978 